\title{
The outcome of COVID-19 in patients with hematological malignancy
}

\author{
Pınar Tığlıŏlu (D) - Murat Albayrak (D) - Mesut Tığlıŏlu (D) - Hacer Berna Afacan Öztürk (D) Merih Reis Aras (D) \\ Buğra Sağlam (D) - Senem Maral (D)
}

Received: 26 September 2021 / Accepted: 8 November 2021 / Published online: 9 December 2021

(C) The Author(s), under exclusive licence to Springer-Verlag GmbH Austria, part of Springer Nature 2021

\begin{abstract}
Summary
Objective The aim of this study was to examine the effect of coronavirus disease 2019 (COVID-19) on the malignancy-related clinical course and overall survival, and to determine the factors affecting mortality. Methods This retrospective study included 77 patients with hematological cancer and COVID-19. Patients were sub-grouped for analysis as survivors and nonsurvivors.

Results COVID-19 was seen more frequently in myeloproliferative neoplasms (MPN), non-Hodgkin lymphoma (NHL) and multiple myeloma (MM) patients. Mortality rate due to COVID-19 was $20.8 \%$. No statistically significant difference was determined between the survivor and non-survivor groups with respect to age and gender, presence of any comorbidity, leukocyte, neutrophil, lymphocyte, and monocyte values. Platelet count and hemoglobin count were signifi-
\end{abstract}

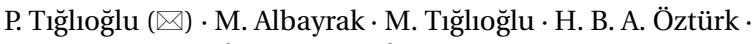
M. R. Aras · B. Sağlam · S. Maral

Diskapi Yildirim Beyazit Training and Research Hospital, Department of Hematology, University of Health Sciences, Ankara, Turkey dr.pinarakyol@hotmail.com

M. Albayrak

muratalbayrak71@yahoo.com

M. Tığlıŏlu

drmesuttiglioglu@gmail.com

H. B. A. Öztürk

bernaafacan@yahoo.com

M. R. Aras

merihreis@gmail.com

B. Sağlam

mdbugra@gmail.com

S. Maral

senemmaral@gmail.com cantly lower in the group with mortality than in the group with recovery.

Conclusion It should be kept in mind that low hemoglobin and platelet levels contribute to mortality. In addition, it is important to protect patients with hematological cancer from COVID-19 and undertake effective vaccination due to its mortal course.

Keywords Cancer - Coronavirus disease 2019 .

Hematological malignancies · Platelet count .

Hemoglobin

\section{Introduction}

Coronavirus disease 2019 (COVID-19) was declared a global pandemic by the World Health Organization (WHO) on 11 March 2020 [1]. Patients with comorbidities such as hypertension (HT), cardiovascular disease, diabetes mellitus (DM), chronic obstructive pulmonary disease (COPD), and cancer are at greater risk of COVID-19 infection and have worse clinical outcomes [2, 3]. Immunosuppression is an important risk factor for COVID-19 disease. Previous studies have shown the prevalence of cancer in COVID-19 patients to be $2 \%$ [4], $3.7 \%$ of patients with COVID-19 are immunodeficient $[5,6]$.

The survival of patients with hematological malignancies has increased due to improved treatment options and better medical care. However, immunosuppression in these patients resulting from both the biology of the disease and the treatments may have an adverse effect on the course of COVID-19. In this context, infections impair the quality of life of patients and even increase mortality [7].

The aim of this study was to evaluate patients who were being followed up for malignant hematological diseases and developed COVID-19, to examine the effect of the COVID-19 infection on the malignancy-re- 
lated clinical course and overall survival and to determine the factors affecting mortality.

\section{Patients and methods}

This retrospective study included patients with a history of malignant hematological disease and COVID19 who were followed up in the Hematology Department of Diskapi Yildirim Beyazit Training and Research Hospital. Nine specific types of hematological malignancies were examined: acute lymphoid leukemia (ALL), acute myeloid leukemia (AML), chronic myeloid leukemia (CML), chronic lymphoid leukemia (CLL), myelodysplastic syndrome (MDS), hodgkin lymphoma (HL), non-Hodgkin lymphoma (NHL), multiple myeloma and Philadelphia chromosome $(\mathrm{Ph})$ negative myeloproliferative neoplasms (MPN).

Patients who presented at the hematology clinic between 01 April 2020 and 31 December 2020 and had a history of COVID-19 infection participated in the study. A confirmed COVID-19 diagnosis was accepted as positivity in the polymerase chain reaction (PCR)based test of a specimen on a nasopharyngeal swab or typical findings on thorax computed tomography (CT). Data for analysis in the study were retrieved from hospital records, Public Health Management System (HSYS) patient files and the MERNIS death notification system.

Demographic and clinical information about both hematological disease and COVID-19 were recorded. Diagnosis, disease status which was classified in 4 groups as initial diagnosis, remission, stable, or relapsed/refractory disease and treatment protocols were recorded for the hematological disease. For COVID-19, symptoms, severity of infection, hospitalization, need for mechanical ventilation or intensive care, COVID-related treatments and mortality were recorded. COVID-19 severity was defined as mild (outpatient), moderate (hospitalization) or severe (ICU).

Patients were sub-grouped for analysis as hospitalized and non-hospitalized and survivors and non-survivors. These groups were compared with each other, in respect of the characteristics related to the clinical course of COVID-19 and the data related to the hematological disease.

\section{Statistical analysis}

Data obtained in the study were analyzed statistically using SPSS Statistics 27.0 software (IBM, Armonk, NY, USA). Descriptive data were stated as median and range, mean \pm standard deviation (SD) values, or number $(n)$ and percentage (\%). Conformity of the data to normal distribution was assessed with the Kolmogorov-Smirnov test. The independent samples t-test and the Mann-Whitney U-test were used in the analysis of quantitative independent data. The $\mathrm{X}^{2}$ test was applied in the analysis of qualitative independent data, and the Fisher test when $\mathrm{X}^{2}$ test conditions were not met. A value of $p<0.05$ was accepted as statistically significant.

\section{Results}

Evaluation was made of 77 patients with COVID-19 infection, who were being followed up in our clinic for a diagnosis of hematological malignancy. The patients comprised 40 (51.9\%) males and 37 (48.1\%) females with a median age of 60 years (range 27-93 years). At least one comorbidity was determined in 46 (59.7\%) patients, primarily HT $(n: 28), \mathrm{DM}(n: 22)$ and COPD $(n: 14)$. The demographic and clinical characteristics of the patients are given in Table 1.

The COVID-19 diagnosis was based on PCR test positivity in $67(87.0 \%)$ patients; in 10 (13.0\%) patients, the PCR test was negative and the diagnosis was confirmed from CT scan findings.

COVID-19 was seen more frequently in patients with MPN (22.1\%), NHL (19.5\%) and MM (15.6\%). Active treatment of chemotherapy, immunotherapy or immunosuppressive therapy were being received by $43(55.8 \%)$ patients. The most common treatments were hydroxyurea (HU), R-CHOP (rituximab, cyclophosphamide, doxorubicine, vincristine, prednisone) chemotherapy regimen and lenalidomide and dexamethasone with one of the proteasome inhibitors. The data of the hematological diagnoses of the patients are shown in Table 2 .

When the clinical course of COVID-19 was examined; $56(72.7 \%)$ patients were symptomatic and the most common symptoms were fever (81\%), cough $(74 \%)$ and weakness $(69 \%)$. Hospitalization was required by $39(50.6 \%)$ patients and median duration length of stay in hospital was 8 days (range 2-30 days). Intensive care was required by 16 patients, all of whom were intubated. The most used agents in the treatment of COVID-19 infection were favipiravir and hydroxychloroquine. Details of the clinical course of COVID-19 and the treatments applied are given in Table 1.

Mortality due to COVID-19 infection developed in 16 patients, giving a mortality rate of $20.8 \%$. The median time from COVID diagnosis to death was 8 days (range 3-53 days). The hematological diagnoses of the exitus patients were $2 \mathrm{AML}, 3 \mathrm{MPN}, 2 \mathrm{MM}, 4 \mathrm{CLL}$ 2 MDS and 3 NHL.

Comparisons were made between patients requiring hospitalization and patients being followed up at home and the data are shown in Table 3 . The hospitalized patients were seen to be significantly older $(p<0.05)$ and there was no significant difference in gender distribution ( $p>0.05)$. DM and COPD presence was significantly higher in the hospitalized group than the non-hospitalized group $(p<0.05)$. Leukocyte, neutrophil, lymphocyte and monocyte counts did not differ significantly between the groups 
Table 1 Clinical data of patients on the course of COVID19 infection

\begin{tabular}{|c|c|}
\hline $\begin{array}{l}\text { The age of the patient at the time of covid-19 diagnosis, } \\
\text { median (min-max) }\end{array}$ & $60(27-93)$ \\
\hline \multicolumn{2}{|l|}{ Sex, $n$ (\%) } \\
\hline Female & $37(48.1 \%)$ \\
\hline Male & $40(51.9 \%)$ \\
\hline \multicolumn{2}{|l|}{ Comorbidity n (\%) } \\
\hline No & $31(40.3 \%)$ \\
\hline Yes & $46(59.7 \%)$ \\
\hline \multicolumn{2}{|l|}{ Comorbidities, $n$} \\
\hline Hypertension & 28 \\
\hline Diabetes & 22 \\
\hline CAD & 13 \\
\hline Congestive heart failure & 2 \\
\hline Hyperlipidemia & 10 \\
\hline Lung disease (COPD, asthma) & 14 \\
\hline CKD (eGFR <60 mL/min) & 1 \\
\hline Chronic hepatitis & 2 \\
\hline Rheumatoid arthritis & 2 \\
\hline History of other malignancy & 2 \\
\hline \multicolumn{2}{|l|}{ COVID PCR, $n$ (\%) } \\
\hline Positive (+) & $67(87.0 \%)$ \\
\hline Negative (-) & $10(13.0 \%)$ \\
\hline \multicolumn{2}{|l|}{ Symptom, $n(\%)$} \\
\hline Yes & $56(72.7 \%)$ \\
\hline No & $21(27.3 \%)$ \\
\hline \multicolumn{2}{|l|}{ Symptoms, $n$ (\%) } \\
\hline Fever & $47(81 \%)$ \\
\hline Cough & $43(74 \%)$ \\
\hline Dyspnea & $19(33 \%)$ \\
\hline Weakness & $40(69 \%)$ \\
\hline Arthralgia & $13(22 \%)$ \\
\hline Myalgia & $9(16 \%)$ \\
\hline Loss of taste and smell & $5(9 \%)$ \\
\hline Throat sore & $4(7 \%)$ \\
\hline Headache & $4(7 \%)$ \\
\hline \multicolumn{2}{|l|}{ Thorax CT finding, $n(\%)$} \\
\hline Yes & $36(46.8 \%)$ \\
\hline No & $41(53.2 \%)$ \\
\hline \multicolumn{2}{|l|}{ Hospitalization, $n$ (\%) } \\
\hline Yes & $39(50.6 \%)$ \\
\hline No & $38(49.4 \%)$ \\
\hline Median length of stay in the hospital, days (min-max) & $8(2-30)$ \\
\hline \multicolumn{2}{|l|}{ Need for intensive care, $n(\%)$} \\
\hline Yes & $16(20.8 \%)$ \\
\hline No & $61(79.2 \%)$ \\
\hline \multicolumn{2}{|l|}{ Invasive mechanical ventilation, $n(\%)$} \\
\hline Yes & $16(20.8 \%)$ \\
\hline No & $61(79.2 \%)$ \\
\hline
\end{tabular}

Table 1 (Continued)

Severity of infection, $n(\%)$

\begin{tabular}{l|l}
\hline Mild & $38(49 \%)$ \\
\hline Moderate & $21(27 \%)$ \\
\hline Severe & $18(24 \%)$ \\
\hline Recovery, $n(\%)$ & $61(79.2 \%)$ \\
\hline Mortality, $n(\%)$ & $16(20.8 \%)$ \\
\hline Treatment, $n(\%)$ & \\
\hline Favipravir & $72(94 \%)$ \\
\hline Hydroxychloroquine & $11(14 \%)$ \\
\hline Pulse corticosteroids & $4(5 \%)$ \\
\hline Tocilizumab & $1(1 \%)$ \\
\hline Anakinra & $1(1 \%)$ \\
\hline Convalescent plasma & $3(4 \%)$ \\
\hline IVIG & $2(3 \%)$ \\
\hline Unknown & $2(3 \%)$ \\
\hline $\begin{array}{l}\text { CAD coronary artery disease, CKD chronic kidney disease, COPD chronic } \\
\text { obstructive pulmonary disease, COVID-19 coronavirus disease } 2019,\end{array}$ \\
$\begin{array}{l}\text { CT computerized tomography, eGFR estimated glomerular filtration rate, } \\
\text { IVIG intravenous immunoglobulin, PCR polymerase chain reaction }\end{array}$
\end{tabular}

Table 2 Demographic and clinical data of the patients regarding their hematological diagnosis Diagnosis, $n$ (\%)

\begin{tabular}{ll}
\hline Acute lymphoblastic leukemia & $2(2.6 \%)$ \\
\hline Acute myeloid leukemia & $5(2.6 \%)$ \\
\hline Non-Hodgkin lymphoma & $15(19.5 \%)$ \\
\hline Hodgkin lymphoma & $5(6.5 \%)$ \\
\hline Chronic lymphocytic leukemia & $11(14.3 \%)$ \\
\hline Chronic myeloid leukemia & $3(3.9 \%)$ \\
\hline Myeloproliferative neoplasms (Ph negative) & $17(22.1 \%)$ \\
\hline Myelodysplastic syndrome & $7(9.1 \%)$ \\
\hline Multiple myeloma & $12(15.6 \%)$ \\
\hline Age median (min-max) & $59(25-91)$ \\
\hline Hematological disease duration, median years (min-max) & $2(0-16)$ \\
\hline Disease status at the time of CoVID-19 diagnosis, $n$ (\%) & \\
Initial diagnosis or first-line treatment & $8(10.4 \%)$ \\
\hline Remission/watch \& wait & $41(53.2 \%)$ \\
Stable & $19(24.7 \%)$ \\
Relapsed/refractory & $9(11.7 \%)$
\end{tabular}

Active chemotherapy/immunotherapy/immunosuppression at the time of COVID-19 diagnosis, $n$ (\%)
Yes
$43(55.8 \%)$
No
$34(44.2 \%)$

COVID-19 coronavirus disease 2019, Ph Philadelphia chromosome

who were hospitalized and not. Platelet value and hemoglobin value were significantly lower $(p<0.05)$ in the hospitalized group than in the non-hospitalized group.

Comparisons were made between the survivor and non-survivor patients and the data are given in Table 4. No statistically significant difference was determined between the survivor and non-survivor groups in respect of age and gender distribution or the presence of any comorbidity and rates of HT, 
Table 3 Clinical characteristics of hospitalized and nonhospitalized patients

\begin{tabular}{|c|c|c|c|}
\hline & Hospitalized & $\begin{array}{l}\text { Non-hospi- } \\
\text { talized }\end{array}$ & $p$ \\
\hline $\begin{array}{l}\text { Age of the patient at the time of } \\
\text { COVID-19 diagnosis (median, } \\
\text { year) }\end{array}$ & 67 & 54.5 & $0.006^{a}$ \\
\hline \multicolumn{3}{|l|}{ Gender, $n(\%)$} & $0.427^{c}$ \\
\hline Female & $17(43.6 \%)$ & $20(52.6 \%)$ & - \\
\hline Male & $22(56.4 \%)$ & $18(47.4 \%)$ & - \\
\hline \multicolumn{3}{|l|}{ Comorbidity, $n$ (\%) } & $0.209^{c}$ \\
\hline Yes & $26(33.3 \%)$ & $18(47.4 \%)$ & - \\
\hline No & $13(66.7 \%)$ & $20(52.6 \%)$ & - \\
\hline Hypertension & $18(46.2 \%)$ & $14(36.8 \%)$ & $0.407^{c}$ \\
\hline Diabetes & $14(35.9 \%)$ & $4(10.5 \%)$ & $0.009^{c}$ \\
\hline COPD & $11(28.2 \%)$ & $3(7.9 \%)$ & $0.021^{c}$ \\
\hline \multicolumn{4}{|l|}{ Hematological diagnosis, $n$ (\%) } \\
\hline ALL & $1(2.6 \%)$ & $1(2.6 \%)$ & $1.000^{\mathrm{C}}$ \\
\hline AML & $2(5.1 \%)$ & $3(7.9 \%)$ & $0.622^{\mathrm{C}}$ \\
\hline NHL & $9(23.1 \%)$ & $6(15.8 \%)$ & $0.420^{c}$ \\
\hline HL & $0(0.0 \%)$ & $5(13.2 \%)$ & $0.019^{c}$ \\
\hline CLL & $8(20.5 \%)$ & $3(7.9 \%)$ & $0.114^{\mathrm{C}}$ \\
\hline CML & $1(2.6 \%)$ & $2(5.3 \%)$ & $0.615^{\mathrm{C}}$ \\
\hline MPN & $6(15.4 \%)$ & $11(28.9 \%)$ & $0.151^{\mathrm{C}}$ \\
\hline MDS & $6(15.4 \%)$ & $1(2.6 \%)$ & $0.052^{\mathrm{C}}$ \\
\hline MM & $6(15.4 \%)$ & $6(15.8 \%)$ & $0.961^{\mathrm{C}}$ \\
\hline \multicolumn{4}{|c|}{ Disease status at the time of COVID-19 diagnosis, $n$ (\%) } \\
\hline $\begin{array}{l}\text { Initial diagnosis/first-line treat- } \\
\text { ment }\end{array}$ & $7(17.9 \%)$ & $1(2.6 \%)$ & $0.028^{c}$ \\
\hline Remission/watch \& wait & $17(43.6 \%)$ & $24(63.2 \%)$ & $0.085^{\mathrm{C}}$ \\
\hline Stable & $10(25.6 \%)$ & $9(23.7 \%)$ & $0.842^{\mathrm{C}}$ \\
\hline Relapsed/refractory & $5(12.8 \%)$ & $4(10.5 \%)$ & $0.754^{\mathrm{C}}$ \\
\hline \multicolumn{3}{|c|}{ Active treatment at the time of COVID-19 diagnosis, $n$ (\%) } & $0.139^{\mathrm{C}}$ \\
\hline Yes & $25(35.9 \%)$ & $18(47.4 \%)$ & - \\
\hline No & $14(64.1 \%)$ & $20(52.6 \%)$ & - \\
\hline Symptom, n (\%) & & & $0.000^{c}$ \\
\hline Yes & $36(92.3 \%)$ & $20(52.6 \%)$ & - \\
\hline No & $3(7.7 \%)$ & $18(47.4 \%)$ & - \\
\hline \multicolumn{3}{|l|}{ Thorax CT finding, $n$ (\%) } & $0.000^{c}$ \\
\hline Yes & $34(87.2 \%)$ & $2(5.3 \%)$ & - \\
\hline No & $5(12.8 \%)$ & $36(94.7 \%)$ & - \\
\hline Wbc $\left(\times 10^{9} / L\right)$ median (range) & $4.1(0.1-83.0)$ & $5.6(0.1-68.0)$ & $0.117^{b}$ \\
\hline $\operatorname{Neu}\left(\times 10^{9} / L\right)$ median (range) & $2.1(0.0-55.0)$ & $3.4(0.0-14.3)$ & $0.154^{b}$ \\
\hline Lym $\left(\times 10^{9} / L\right)$ median (range) & $0.7(0.0-36.8)$ & $1.5(0.0-61.9)$ & $0.094^{b}$ \\
\hline$H b(g r / d L)$ median (range) & $10(6-15)$ & $13(6-16)$ & $0.002^{b}$ \\
\hline PIt $\left(\times 10^{9} / L\right)$ median (range) & $126(4-587)$ & $239(17-635)$ & $0.018^{b}$ \\
\hline \multicolumn{4}{|c|}{$\begin{array}{l}\text { ALL acute lymphoblastic leukemia, } A M L \text { acute myeloid leukemia, CLL chronic } \\
\text { lymphocytic leukemia, CML chronic myeloid leukemia, COPD chronic obstruc } \\
\text { tive pulmonary disease, COVID- } 19 \text { coronavirus disease } 2019, C T \text { computer- } \\
\text { ized tomography, Hb hemoglobin, } H L \text { hodgkin lymphoma, } L y m \text { lymphocyte, } \\
\text { MDS myelodysplastic syndrome, MM multiple myeloma, MPN myeloprolifer- } \\
\text { ative neoplasms, Neu neutrophil, NHL non-Hodgkin lymphoma, Plt platelet, } \\
\text { Wbc white blood cell count } \\
\text { alndependent sample t test } \\
\text { bMann-Whitney U test } \\
{ }^{c} \mathrm{X}^{2} \text { test (Fischer test) }\end{array}$} \\
\hline
\end{tabular}

Table 4 Clinical characteristics of survivors and nonsurvivors

\begin{tabular}{llll} 
& $\begin{array}{l}\text { Non-survivor } \\
(n=16)\end{array}$ & $\begin{array}{l}\text { Survivor } \\
(n=61)\end{array}$ & $p$ \\
$\begin{array}{l}\text { Age of the patient at the time of } \\
\text { COVID-19 diagnosis (median, } \\
\text { years) }\end{array}$ & 70.5 & 59.0 & $0.077^{\mathrm{a}}$ \\
$\begin{array}{l}\text { Gender, } n \text { (\%) } \\
\begin{array}{l}\text { Female } \\
\text { Male }\end{array}\end{array}$ & $8(50 \%)$ & $29(47.5 \%)$ & - \\
\hline $\begin{array}{l}\text { Comorbidity, } n \text { (\%) } \\
\text { Yes }\end{array}$ & $8(50 \%)$ & $32(52.5 \%)$ & - \\
\hline No & $7(43.8 \%)$ & $39(63.9 \%)$ & - \\
\hline Hypertension & $9(56.3 \%)$ & $22(36.1 \%)$ & - \\
\hline Diabetes & $4(25.0 \%)$ & $28(45.9 \%)$ & $0.131^{\mathrm{c}}$ \\
\hline COPD & $4(25.0 \%)$ & $14(23.0 \%)$ & $0.863^{\mathrm{c}}$ \\
\hline Hematological diagnosis, $n(\%)$ & $2(12.5 \%)$ & $12(19.7 \%)$ & $0.508^{\mathrm{c}}$ \\
\hline ALL & & & \\
\hline AML & $0(0.0 \%)$ & $2(3.3 \%)$ & $1.000^{\mathrm{c}}$ \\
\hline NHL & $2(12.5 \%)$ & $3(4.9 \%)$ & $0.276^{\mathrm{c}}$ \\
\hline HL & $3(18.8 \%)$ & $12(19.7 \%)$ & $0.934^{\mathrm{c}}$ \\
\hline CLL & $0(0.0 \%)$ & $5(8.2 \%)$ & $0.577^{\mathrm{C}}$ \\
\hline CML & $4(25.0 \%)$ & $7(11.5 \%)$ & $0.169^{\mathrm{c}}$ \\
\hline MPN & $0(0.0 \%)$ & $3(4.9 \%)$ & $1.000^{\mathrm{c}}$ \\
\hline MDS & $3(18.8 \%)$ & $14(23.0 \%)$ & $0.718^{\mathrm{c}}$ \\
\hline MM & $2(12.5 \%)$ & $5(8.2 \%)$ & $0.631^{\mathrm{c}}$ \\
\hline Dis & $2(12.5 \%)$ & $10(16.4 \%)$ & $0.702^{\mathrm{c}}$
\end{tabular}

Disease status at the time of COVID-19 diagnosis, $n$ (\%)

Initial diagnosis/first-line treat- $\quad 3(18.8 \%) \quad 5(8.2 \%)$ ment

$\begin{array}{llll}\text { Remission/watch \& wait } & 5(31.3 \%) & 36(59.0 \%) & \mathbf{0 . 0 4 8}^{\mathrm{c}}\end{array}$

$\begin{array}{llll}\text { Stable } & 4(25.0 \%) & 15(24.6 \%) & 0.973^{\mathrm{c}}\end{array}$

$\begin{array}{llll}\text { Relapsed/refractory } & 4(25.0 \%) & 5(8.2 \%) & 0.083^{\mathrm{C}}\end{array}$

Active treatment at the time of COVID-19 diagnosis, $n(\%) \quad 0.597^{\mathrm{C}}$

$\begin{array}{llll}\text { Yes } & 8(50.0 \%) & 35(57.4 \%) & -\end{array}$

$\begin{array}{llll}\text { NNo } & 8(50.0 \%) & 26(42.6 \%) & -\end{array}$

Symptom, $n(\%) \quad \mathbf{0 . 0 3 4 ^ { \circ }}$

$\begin{array}{llll}\text { Yes } & 15(93.8 \%) & 41(67.2 \%) & -\end{array}$

$\begin{array}{llll}\text { No } & 1(6.3 \%) & 20(32.8 \%) & -\end{array}$

Thorax CT finding, $n$ (\%) $\quad \mathbf{0 . 0 0 0 ^ { C }}$

$\begin{array}{llll}\text { Yes } & 15(93.8 \%) & 21(34.4 \%) & -\end{array}$

$\begin{array}{lll}\text { No } & 1(6.3 \%) & 40(65.6 \%)\end{array}$

Wbc $\left(\times 10^{9} / L\right)$ median (range) $\quad 3.1(0.1-59.9) \quad 5.6(0.1-83.0) \quad 0.232^{b}$

$\mathrm{Neu}\left(\times 10^{9} /\right.$ L) median (range) $\quad 1.8(0.0-21.4) \quad 3.3(0.0-55.0) \quad 0.263^{\mathrm{b}}$

$\operatorname{Lym}\left(\times 10^{9} /\right.$ L) median (range) $\quad 0.7(0.0-36.8) \quad 1.2(0.0-61.9) \quad 0.696^{\mathrm{b}}$

$\mathrm{Hb}(\mathrm{gr} / \mathrm{dL})$ median (range) $\quad 8(6-13) \quad 12(6-16) \quad \mathbf{0 . 0 0 3 ^ { \mathrm { b } }}$

$\begin{array}{llll}\text { Plt }\left(\times 10^{9} / L\right) \text { median (range) } \quad 54(10-588) & 204(4-635) & \mathbf{0 . 0 0 2}\end{array}$

Hospitalization, $n(\%) \quad 0.000^{\mathrm{C}}$

$\begin{array}{llll}\text { Yes } & 16(100.0 \%) & 23(37.7 \%) & -\end{array}$

No $\quad 0(0.0 \%) \quad 38(62.3 \%) \quad$ -

Number of days of hospitalization $6 \quad 9.923^{b}$

(median)

Need for intensive care, $n(\%) \quad 0.000^{c}$

$\begin{array}{llll}\text { Yes } & 13(81.3 \%) & 3(4.9 \%) & -\end{array}$

No $3(18.7 \%) \quad 58(95.1 \%)$ - 
Table 4 (Continued)

\begin{tabular}{l|lll} 
& $\begin{array}{c}\text { Non-survivor } \\
(n=16)\end{array}$ & $\begin{array}{l}\text { Survivor } \\
(n=61)\end{array}$ & $p$ \\
\hline Invasive mechanical ventilation, $n(\%)$ & & $\mathbf{0 . 0 0 0}$ \\
\hline Yes & $15(93.8 \%)$ & $1(1.6 \%)$ & - \\
\hline No & $1(6.3 \%)$ & $60(98.4 \%)$ & -
\end{tabular}

ALL acute ALL, ALL acute lymphoblastic leukemia, $A M L$ acute myeloid leukemia, CLL chronic lymphocytic leukemia, CML chronic myeloid leukemia, COPD chronic obstructive pulmonary disease, COVID-19 coronavirus disease 2019, CT computerized tomography, $H b$ hemoglobin, $H L$ hodgkin lymphoma, Lym lymphocyte, MDS myelodysplastic syndrome, MM multiple myeloma, MPN myeloproliferative neoplasms, Neu neutrophil, $N H L$ non-Hodgkin lymphoma, Plt platelet, Wbc white blood cell count

aIndependent sample t test

${ }^{\mathrm{b}}$ Mann-Whitney U test

${ }^{c} \mathrm{X}^{2}$ test (Fischer test)

DM or COPD ( $p>0.05$ for all). No significant difference was determined between the survivor and nonsurvivor groups in respect of leukocyte, neutrophil, lymphocyte and monocyte values $(p>0.05)$. Platelet count and hemoglobin count were significantly lower in the group with mortality than in the group with recovery $(p<0.0)$.

\section{Discussion}

Most patients with blood cancer have a suppressed immune system because of the biology of the malignancy itself and cancer treatments. Although current chemotherapy, radiotherapy and other immunosuppressive treatments increase the quality of life of patients with hematological cancers and prolong their overall survival, they also suppress the cellular and humoral immunity of patients, thereby making them vulnerable to infections. Moreover, the advanced age of most of these patients and their comorbidities also increase the risk of infection $[8,9]$. In this context, it can be thought that the course of COVID-19 may be more aggressive and mortality may be higher in patients with hematological malignancies.

In a previous study, COVID-19 was most commonly detected in patients with CLL (39.4\%) and MM (33.3\%) [7]. The ASH Research Collaborative COVID-19 Registry reported that acute leukemia (33\%), NHL (27\%) and myeloma or amyloidosis $(16 \%)$ were the most common blood cancers in patients diagnosed with COVID-19 [10]. In this study, COVID-19 was most commonly seen in patients with MPN, NHL, and MM respectively. Although patients with MPN have less immunosuppression, in the context of this study, the most frequent occurrence of COVID-19 in this group is probably due to the high percentage of MPN cases among the hematological malignancies.

The majority of patients with COVID-19 infection are asymptomatic or have mild to moderate symptoms. Cough, fever, dyspnea, musculoskeletal symptoms (myalgia, joint pain, fatigue) are the most frequently reported symptoms [11, 12]. The most common symptoms in the patients in this study were fever, weakness, and cough, similar to the general population. In previous studies, the rate of asymptomatic cases has been reported to be around 56-58\% [13, 14]. In our study, most of the cases were symptomatic and the rate of asymptomatic patients was $27.3 \%$; $50.6 \%$ of patients were hospitalized, with a higher rate determined in patients with hypertension and COPD and in older patients.

Severe pneumonia develops in $15 \%$ of patients and $5 \%$ of patients need intensive care unit (ICU) management [15]. In this study, the need for invasive mechanical ventilation (20.8\%) and follow-up in ICU (20.8\%) was found to be higher in patients with hematological cancer compared to non-cancer cases described in the literature.

In studies involving patients with hematological cancer, COVID-19 mortality has been reported in the range of 32 to $61 \%[16,17]$. In our study, mortality developed in 16 of the total 77 patients at a mortality rate of $20.8 \%$. Compared with the literature, the mortality rate in this study was lower than that of patients with hematological cancer, but higher than that of the healthy population [15]. The reason for this may be bone marrow suppression and cytopenia, chemotherapy and the immunosuppressive agents used in the treatment of hematological cancer patients.

In patients with hematological cancer, risk factors such as age, comorbidities and the severity of COVID19 clinical course have been reported to be associated with mortality [18]. In the comparison of this study's surviving and non-surviving patients, as expected, mortality was higher in patients who were symptomatic, had thorax CT findings, were intubated and were transferred to the intensive care unit.

Interestingly, disease subtype, disease state, comorbidity and age were not found to have an effect on mortality in this study. A large, population-based, Spanish study showed that diagnosis of AML and MDS was related to mortality [19]. In a study from Italy, advanced age, progressive hematological disease, and severe COVID-19 pneumonia were stated as risk factors for mortality [7]. Cattaneo et al. determined that the status of receiving active chemotherapy or immunosuppressive was the most important parameter associated with the risk of death [20]. The heterogeneity of the hematological diagnoses of the patients and the treatments given made it difficult to analyze the effect of treatment on mortality.

In this study, it was observed that low hemoglobin and low platelet count were associated with both hospitalization and mortality. Similarly, in a previous review, it was stated that a decrease in platelet count was associated with mortality [21]. In a study by Shang et al., platelet levels were found to be lower in patients with severe disease [22]. Another retrospective single-center study demonstrated that thrombocytopenia was related with mortality in patients with COVID19 [23]. According to the same study results, as the 
platelet counts decreased, the mortality rate increased [24].

Thrombopoetin, which is released from the liver in response to infection, may help prevent lung specific entry by increasing the lung megakaryocytes in the lungs and increasing the number of platelets. According to this hypothesis, in patients with decreased platelet count, it is easier for the virus to enter the lungs, thereby explaining the relationship of severe pneumonia with mortality. It is also known that in severe pulmonary involvement, endothelial damage triggers thrombocyte activation and aggregation and this may cause platelet depletion [25]. Furthermore, this information may explain the low platelet counts in patients with mortality. However, bone marrow suppression or therapy-related thrombocytopenia, which are common in patients with hematological cancer, also confuse the results.

In this study, low hemoglobin levels were also found to be associated with mortality. In a study of 1099 COVID-19 cases, patients with anemia had worse clinical outcomes [26]. In another study, it was shown that low hemoglobin levels were associated with severe disease [27]. Many studies have shown that anemia worsens the course of pulmonary diseases and increases mortality [28, 29]. The reason for the higher mortality of patients with COVID-19 with low hemoglobin may be that oxygenation is impaired in anemia and tissue hypoxia aggravates the infection and that anemic patients are both older and tend to be patients with comorbidities. Low hemoglobin levels were seen to be common in the current study group with hematological cancer.

There were some limitations to this study, primarily the retrospective design and that it was conducted in a single center with a small number of patients so it is difficult to generalize the results.

\section{Take-home message}

- The aim of this study was to examine the course of COVID-19 (coronavirus disease 2019) in patients with hematological malignancies and to determine the factors affecting the severity of the infection.

- It should be kept in mind that low hemoglobin and platelet levels contribute to mortality. In addition, it is important to protect patients with hematological cancer from COVID-19 infection and undertake eff ective vaccination due to its more aggressive and $\mathrm{m}$ ortal course than for patients without a malignancy.

- Further studies and long-term observations are required with a larger number of patients to determine predictive factors associated with the severity of the clinical course and mortality.

Funding This research did not receive any specific grant from funding agencies in the public, commercial, or not-for-profit sectors.

\section{Declarations}

Conflict of interest P. Tığlıoğlu, M. Albayrak, M. Tığlıoğlu, H.B.A. Öztürk, M.R. Aras, B. Sağlam and S. Maral declare that they have no competing interests, including specific financial interests, relationships, and/or affiliations relevant to the subject matter or materials included.

Ethical standards All procedures performed in this study were conducted in accordance with the ethical standards of the institutional and/or national research committee and the 1964 Declaration of Helsinki and its subsequent amendments or comparable ethical standards. Approval for this study was granted by the Republic of Turkey Ministry of Health and the Local Ethics Committee.

\section{References}

1. Zhou F, Yu T, Du R, et al. Clinical course and risk factors for mortality of adult inpatients with COVID-19 in Wuhan, China: a retrospective cohort study. Lancet. 2020;395(10229):1054-62.

2. Guan W, Liang W, Zhao Y, et al. Comorbidity and its impact on 1590 patients with COVID-19 in China: a nationwide analysis. Eur Respir J. 2020;55:5.

3. Wang B, Li R, Lu Z, et al. Does comorbidity increase the risk of patients with COVID-19: evidence from meta-analysis. Aging (Albany NY). 2020;12(7):6049.

4. Desai A, Sachdeva S, Parekh T, et al. COVID-19 and cancer: lessons from a pooled meta-analysis. JCO Glob Oncol. 2020;6:557-9.

5. Team CC-R, Team CC-R, Team CC-R, et al. Preliminary estimates of the prevalence of selected underlying health conditions among patients with coronavirus disease 2019-United States, February 12-March 28, 2020. MMWR Morb Mortal Wkly Rep. 2020;69(13):382-6.

6. Mehta V, Goel S, Kabarriti R, et al. Case fatality rate of cancer patients with COVID-19 in a New York hospital system. Cancer Discov. 2020;10(7):935-41.

7. Passamonti F, Cattaneo C, Arcaini L, et al. Clinical characteristics and risk factors associated with COVID-19 severity in patients with haematological malignancies in Italy: a retrospective, multicentre, cohort study. Lancet Haematol. 2020;7(10):e737-e45.

8. Connors JM, Levy JH. COVID-19 and its implications for thrombosis and anticoagulation. Blood. 2020;135(23):2033-40.

9. Fontana L, Strasfeld L. Respiratory virus infections of the stem cell transplant recipient and the hematologic malignancy patient. Infect Dis Clin North Am. 2019;33(2):523-44.

10. Wood WA, Neuberg DS, Thompson JC, et al. Outcomes of patients with hematologic malignancies and COVID-19: a report from the ASH Research Collaborative Data Hub. Blood Adv. 2020;4(23):5966-75.

11. Goyal P, Choi JJ, Pinheiro LC, et al. Clinical characteristics of Covid-19 in New York city. N Engl J Med. 2020;382(24):2372-4.

12. Huang C, Wang Y, Li X, et al. Clinical features of patients infected with 2019 novel coronavirus in Wuhan, China. Lancet. 2020;395(10223):497-506.

13. Arons MM, Hatfield KM, Reddy SC, et al. Presymptomatic SARS-CoV-2 infections and transmission in a skilled nursing facility. NEngl J Med. 2020;382(22):2081-90.

14. Sakurai A, Sasaki T, Kato S, et al. Natural history of asymptomatic SARS-CoV-2 infection. N Engl J Med. 2020;383(9):885-6. 
15. Wu Z, McGoogan JM. Characteristics of and important lessons from the coronavirus disease 2019 (COVID-19) outbreakin China: summary of a report of 72314 cases from the Chinese Center for Disease Control and Prevention. JAMA. 2020;323(13):1239-42.

16. He W, Chen L, Chen L, et al. COVID-19 in persons with haematological cancers. Leukemia. 2020;34(6):1637-45.

17. Martín-Moro F, Marquet J, Piris M, et al. Survival study of hospitalised patients with concurrent COVID19 and haematological malignancies. $\mathrm{Br} J$ Haematol. 2020;190(1):e16-e20.

18. Zhu N, Zhang D, Wang W, et al. A novel coronavirus from patients with pneumonia in China, 2019. N Engl J Med. 2020;382(8):727-733. https://doi.org/10.1056/ NEJMoa2001017

19. García-Suárez J, De La Cruz J, Cedillo Á, et al. Impact of hematologic malignancy and type of cancer therapy on COVID-19 severity and mortality: lessons from a large population-based registry study. J Hematol Oncol. 2020;13(1):1-12.

20. Cattaneo C, Daffini R, Pagani C, et al. Clinical characteristics and risk factors for mortality in hematologic patients affected by COVID-19. Cancer. 2020;126(23):5069-76.

21. Kim JS, Lee KH, Kim G, et al. Clinical characteristics and mortality of patients with hematologic malignancies and COVID-19: a systematic review. Eur Rev Med Pharmacol Sci. 2020;24(22):11926-33.

22. Shang W, Dong J, Ren Y, et al. The value of clinical parameters in predicting the severity of COVID-19. J Med Virol. 2020;92(10):2188-92.

23. Lefrançais E, Ortiz-Muñoz G, Caudrillier A, et al. The lung is a site of platelet biogenesis and a reservoir for haematopoietic progenitors. Nature. 2017;544(7648):105-9.
24. Yang X, Yang Q, Wang Y, et al. Thrombocytopenia and its association with mortality in patients with COVID- 19 . J Thromb Haemost. 2020;18(6):1469-72.

25. Yang M, Ng MH, Li CK. Thrombocytopenia in patients with severe acute respiratory syndrome (review). Hematology. 2005;10(2):101-5.

26. Guan WJ, Ni ZY, Hu Y, et al. Clinical characteristics of Coronavirus disease 2019 in China. N Engl J Med. 2020;382(18):1708-20.

27. Anai M, Akaike K, Iwagoe $\mathrm{H}$, et al. Decrease in hemoglobin level predicts increased risk for severe respiratory failure in COVID-19 patients with pneumonia. Respir Investig. 2021;59(2):187-93.

28. Doshi S, Rueda A, Corrales-Medina V, et al. Anemia and community-acquired pneumococcal pneumonia. Infection. 2011;39(4):379-83.

29. Reade MC, Weissfeld L, Angus DC, et al. The prevalence of anemia and its association with 90-day mortality in hospitalized community-acquired pneumonia. BMCPulm Med. 2010;10(1):1-10.

Publisher's Note Springer Nature remains neutral with regard to jurisdictional claims in published maps and institutional affiliations.

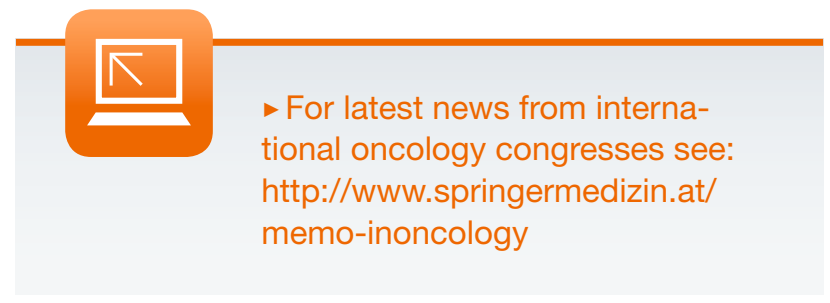

